\title{
Chronic Subdural Hematomas: An Institutional Review of 24 Operated Patients
}

\author{
Jaykumar Gunjkar ${ }^{1}$, SS Vhora ${ }^{2}$, Vishal Pingalkar ${ }^{3}$ \\ ${ }^{1}$ Assistant Professor, Department of Neurosurgery, BJ Medical College, ${ }^{2}$ Professor, Department of Neurosurgery, BJ Medical \\ College, ${ }^{3}$ Senior Resident, Department of Neurosurgery, BJ Medical College, India
}

Corresponding author: Dr Jaykumar Gunjkar,Richwood soc,F/501, Spine Road, Chikhli PCNT, Chinchwad, Pune, 411019

DOI: http://dx.doi.org/10.21276/ijcmsr.2019.4.3.11

How to cite this article: Jaykumar Gunjkar, SS Vhora, Vishal Pingalkar. Chronic subdural hematomas: an institutional review of 24 operated patients. International Journal of Contemporary Medicine Surgery and Radiology. 2019;4(3):C48-C51.

\section{A B S T R A C T}

Introduction: chronic subdural Hematoma is one of the most common neurosurgical entity encountered by a neurosurgeon. Incidence of chronic subdural Hematoma in general population is increasing in view of increase in the elderly population. In this study we have tried to put light on factors which are responsible for development of chronic subdural hematomas and its poor prognosis.

Material and methods: The patients were prospectively evaluated. Demographic variables, CT scan variables and clinical variables was studied to predict poor outcomes in the form of recurrence in operated cases of chronic subdural hematomas. Results: 24 patients were studied. 19 were males and 5 were females. Mean age was 64.7 years. Recurrence was seen in 7 cases. Recurrence in males was $26.1 \%$ while in females it was $40 \%$. Symptoms at diagnosis has no significance in recurrence. Thrombocytopenia, antiplatelet use and anticoagulant use was significantly associated with recurrence. Mixed density hematomas recur more.

Conclusions: If treated properly and meticulously chronic subdural hematomas give a very rewarding results. Antiplatelet use, anticoagulant use, and bilateral subdural hematomas are associated with poor prognosis. Preoperative evaluation of patients and postoperative management becomes very important in view of elderly population.

Keywords: Chronic Subdural Hematomas

\section{INTRODUCTION}

Chronic subdural Hematoma is one of the most common neurosurgical condition encountered by a neurosurgeon in his day to day practice. The occurrence rate is estimated to be 1to 2 cases per 1 lakh population per year. ${ }^{3}$ This is generally thought as the disease of the elderly and has a very typical history of onset and progression. The overall incidence of this disease is increasing because of our aging population and also because of the widespread use of radiological techniques like CT scan and MRI. Some cases are also difficult to diagnose because of atypical presentation. ${ }^{1-5}$ Also because of common use of drugs such as antiplatelets and anticoagulants incidence is increasing. In this study we have tried to put light on factors which are associated with development of chronic subdural hematomas and its poor prognosis.

\section{MATERIAL AND METHODS}

This study was undertaken at neurosurgery department of BJ medical college and sassoon General Hospital of Pune over a period of one year that is March 2017 to March 2018. All the patients were prospectively evaluated. Recurrent hematomas and hematomas that occurred due to non drug induced coagulopathy were excluded from the study. Computed tomography was used to diagnose all cases. The demographic information which was collected was a age and sex of the patient. All routine blood investigation results and information regarding use of antiplatelet medications and anticoagulants were taken from the case file of the patient. The CT SCANwas studied to characterize the haematoma. The main CT SCAN characteristics which were studied are: a. Density of Hematoma-hypodense or mixed density. Purely hyperdense hematomas were excluded as it indicates acute subdural Hematoma.

b. Midline shift to contralateral side-the midline shift was measured at the level of the third ventricle.

c. Maximum thickness of the Hematoma was measured.

\section{Surgical Management}

Standard surgical procedure was performed in all the selected patients. Two burr holes were made in all patients depending upon the position of maximum thickness of the Hematoma. Linear incisions were used. The dura and the membrane immediately beneath the during was opened and the Hematoma was drained off. The subdural space was copiously irrigated with saline till the returning fluid is clear. An external continuous drain in the form of minivac drain was kept for 2 to 3 days. The patient was advised to be supine without head elevation. CT scan was done if there is no improvement in symptoms after surgery or there is 
deterioration after some improvement or routine at the time of discharge. The following factors were studied to evaluate the risk of recurrence and poor outcome.

a. Demographic variables: age and sex.

b. Symptoms on presentation: headache, motor weakness, mental changes.

c. Underlying diseases: history of trauma, hypertension, Diabetes mellitus, chronic renal failure, anticoagulant use, antiplatelet use, thrombocytopenia.

d. CT scan characteristics: density of Hematoma like hypodense or mixed density, Midline shift more than 10 millimetres or less than $10 \mathrm{~mm}$, Unilateral or bilateral Hematoma.

e. Intraoperative findings: presence of thick outer membrane. Presence of big subdural cavity after evacuation. Subjective assessment was done for about two characteristics.

\section{RESULTS}

We studied 24 patients operated for chronic subdural hematomas. 19 were males and the remaining 5 were females. The mean age of all the patient taken together was 64.7 years. Recurrence was seen in total of seven patients.

\begin{tabular}{|c|c|c|}
\hline Variable & $\begin{array}{c}\text { Non Recurrence } \\
\text { (17) }\end{array}$ & Recurrence (7) \\
\hline \multicolumn{3}{|l|}{ Sex } \\
\hline Female (5) & $3(60 \%)$ & $2(40 \%)$ \\
\hline Male (19) & 14 (73.69\%) & $5(26.31 \%)$ \\
\hline \multicolumn{3}{|l|}{ Symptoms } \\
\hline Headache (17) & $13(76.41 \%)$ & $4(23.59 \%)$ \\
\hline Motor weakness (5) & $3(60 \%)$ & $2(40 \%)$ \\
\hline Mental changes (2) & 1 (50\%) & 1 (50\%) \\
\hline \multicolumn{3}{|l|}{ History of trauma } \\
\hline Present (16) & $11(68.75 \%)$ & 5 (31.25\%) \\
\hline Not Present (8) & $6(75 \%)$ & $2(25 \%)$ \\
\hline \multicolumn{3}{|l|}{ Underlying diseases } \\
\hline Hypertension (9) & $7(77.77 \%)$ & $2(22.23 \%)$ \\
\hline Diabetes mellitus (6) & $4(66.66 \%)$ & $2(33.33 \%)$ \\
\hline Chronic renal failure (4) & $3(75 \%)$ & $1(25 \%)$ \\
\hline Anticoagulant use (4) & $1(25 \%)$ & $3(75 \%)$ \\
\hline Anti Platelet use (4) & $2(50 \%)$ & $2(50 \%)$ \\
\hline Thrombocytopenia (1) & 0 & $1(100 \%)$ \\
\hline \multicolumn{3}{|l|}{ Density of haematoma } \\
\hline Hypodense (18) & $15(83.33 \%)$ & $3(16.67 \%)$ \\
\hline Mixed density (6) & $2(33 \%)$ & $4(76 \%)$ \\
\hline \multicolumn{3}{|l|}{ Midline shift } \\
\hline$<10 \mathrm{~mm}(19)$ & 15 (78.94\%) & $4(21.06 \%)$ \\
\hline$\geq 10 \mathrm{~mm}(5)$ & $2(40 \%)$ & $3(60 \%)$ \\
\hline \multicolumn{3}{|l|}{ Laterality } \\
\hline Unilateral (21) & 16 (76.19\%) & $5(23.18 \%)$ \\
\hline Bilateral (3) & $1(33.33 \%)$ & $2(66.67 \%)$ \\
\hline \multicolumn{3}{|l|}{ Thick Membrane } \\
\hline Present (6) & $2(33.33 \%)$ & $4(66.67 \%)$ \\
\hline Not Present (18) & $15(83.33 \%)$ & $3(16.69 \%)$ \\
\hline \multicolumn{3}{|l|}{ Big Subdural space } \\
\hline Present (9) & $3(33.33 \%)$ & $6(66.67 \%)$ \\
\hline Not Present (15) & 14 (93.33\%) & $1(6.67 \%)$ \\
\hline
\end{tabular}

\begin{tabular}{|c|c|c|}
\hline \multicolumn{3}{|l|}{ Sex } \\
\hline Female (5) & $3(60 \%)$ & $2(40 \%)$ \\
\hline Male (19) & $14(73.69 \%)$ & 5 (26.31\%) \\
\hline \multicolumn{3}{|l|}{ Symptoms } \\
\hline Headache (17) & $13(76.41 \%)$ & $4(23.59 \%)$ \\
\hline Motor weakness (5) & $3(60 \%)$ & $2(40 \%)$ \\
\hline Mental changes (2) & $1(50 \%)$ & $1(50 \%)$ \\
\hline \multicolumn{3}{|l|}{ History of trauma } \\
\hline Present (16) & $11(68.75 \%)$ & $5(31.25 \%)$ \\
\hline Not Present (8) & $6(75 \%)$ & $2(25 \%)$ \\
\hline \multicolumn{3}{|l|}{ Underlying diseases } \\
\hline Hypertension (9) & $7(77.77 \%)$ & $2(22.23 \%)$ \\
\hline Diabetes mellitus (6) & $4(66.66 \%)$ & $2(33.33 \%)$ \\
\hline Chronic renal failure (4) & $3(75 \%)$ & $1(25 \%)$ \\
\hline Anticoagulant use (4) & $1(25 \%)$ & $3(75 \%)$ \\
\hline Anti Platelet use (4) & $2(50 \%)$ & $2(50 \%)$ \\
\hline Thrombocytopenia (1) & 0 & $1(100 \%)$ \\
\hline \multicolumn{3}{|l|}{ Density of haematoma } \\
\hline Hypodense (18) & $15(83.33 \%)$ & $3(16.67 \%)$ \\
\hline Mixed density (6) & $2(33 \%)$ & $4(76 \%)$ \\
\hline \multicolumn{3}{|l|}{ Midline shift } \\
\hline$<10 \mathrm{~mm}(19)$ & $15(78.94 \%)$ & $4(21.06 \%)$ \\
\hline$\geq 10 \mathrm{~mm} \mathrm{(5)}$ & $2(40 \%)$ & $3(60 \%)$ \\
\hline \multicolumn{3}{|l|}{ Laterality } \\
\hline Unilateral (21) & $16(76.19 \%)$ & $5(23.18 \%)$ \\
\hline Bilateral (3) & $1(33.33 \%)$ & $2(66.67 \%)$ \\
\hline \multicolumn{3}{|l|}{ Thick Membrane } \\
\hline Present (6) & $2(33.33 \%)$ & $4(66.67 \%)$ \\
\hline Not Present (18) & $15(83.33 \%)$ & $3(16.69 \%)$ \\
\hline \multicolumn{3}{|l|}{ Big Subdural space } \\
\hline Present (9) & $3(33.33 \%)$ & $6(66.67 \%)$ \\
\hline Not Present (15) & $14(93.33 \%)$ & $1(6.67 \%)$ \\
\hline
\end{tabular}

The recurrence rate in males was $26.1 \%$ and the recurrence rate in female was 40\%. Difference in recurrence rate among males and females was found to be clinically significant but as discussed with the statistician it might not be truly significant in view of small sample size of female patients. Headache was the most common presentation in our series. $83 \%$ had headache followed by motor weakness which was present in $20.83 \%$ of patients and mental changes which was present in 8.33 percent of the patients. Presenting symptom at the time of diagnosis does not have any clinically relevant significance on the recurrence rate. Out of 24 patients history of trauma could be initiated in 16 patients. There was no clinically significant difference in the rate of recurrence when history of trauma was considered as a variable. When comorbid conditions were considered as a variable multiple Logistic regression analysis could not be applied as more than one variable was present in some patients but when the percentages were analysed it could be inferred that patients with thrombocytopenia, anticoagulant used and antiplatelet use were more prone to develop recurrence. Density of Hematoma in the preoperative scan was a clinically significant variable. Recurrence was $76 \%$ in mixed density hematomas as compared to $16.67 \%$ recurrence in hematomas 
which were exclusively bypodense. The recurrence rate was higher that is $60 \%$ in hematomas with midline shift of more than or equal to $10 \mathrm{~mm}$ then in hematomas with less than 10 $\mathrm{mm}$ midline shift. In our analysis though the intraoperative variables are associated with increased occurrence but it was not clinically significant (Table-1).

\section{DISCUSSION}

Many studies have been done so far to study the prognostic factors for operated cases of chronic subdural hematomas and also to study the factors associated with recurrence. However the same risk factors are generally not consistent across studies. Here we have attempted to study the risk factors in our set of patients. Chronic subdural Hematoma is generally considered as the disease of the aging brain. The main reason for the same is age related decrease in the brain volume. This in turn leads to development of potential subdural space in the elderly brain and development of tension in the intervening bridging veins. Also there is increased fragility of bridging veins. Trivial trauma can lead to breakage of veins and development of subdural clots. In our group the incidence in male population is more than in females. This correlates well with other studies. ${ }^{2,3,4,5}$ Males and more prone to develop head injuries and so chronic subdural hematomas are more common in males. Also there is a hypothesis that oestrogen plays a protective role in females and it is known to induce vascular repair and angiogenesis. ${ }^{4,11}$ In our study the recurrence is more in females but this seems to be not significant in view of small sample size of females. History of trivial trauma was present in significant number of our patients and this is consistent with other literature. ${ }^{11-19}$ This trivial trauma leads to development of small subdural clots which further leads to development of membranes and formation of chronic subdural hematomas. There are many hypothesis but the most common hypothesis is that of angiogenesis in the membrane and continuous secretory activity.

But a significant number of patients also tend to forget tbe history of trivial trauma, so even though the occurrence of chronic subdural Hematoma is absolutely not proportional to history of trauma but it is a very important factor in development of chronic subdural Hematoma. Even though the symptoms vary between various patients the common ones are headache, motor deficits and mental changes. The nature of symptoms does not correlates with recurrence in our study as in most other studies. ${ }^{4,6,17,19} \mathrm{In}$ this regard we would like to reiterate that all the primary care physician should consider the chances of occurrence of chronic subdural Hematoma in elderly patients with neurological deficits and mental changes. Comorbid conditions like hypertension, diabetes and chronic renal failure are not significantly associated with occurrence or recurrence of chronic subdural Hematoma but this is a cohort of patients which is more likely to take antiplatelet and anticoagulant medications. There is a definitely positive correlation between recurrence and intake of these medications. Hypodense hematomas tend to recur less than hyperdenseormixed hematomas. The reasons for the same are most likely chances of complete drainage of hypodense hematomas and also less chances of formation of thick membrane. Chemical analysis of hematomas has also shown that the factors like vascular endothelial growth factor and transforming growth factor beta are responsible for more recurrence in chronic subdural hematomas with hyperdense components. ${ }^{4,11}$ More the midline shift more is the recurrence also the bilaterality of the Hematoma is associated with more chances of recurrence. Even though these factors are not clinically significant they indicates more severe disease and ultimately poor prognosis. We have studied some intraoperative variables which are not studied in most other studies of chronic subdural Hematoma. The presence of thick subdural membrane indicates increase vascularity and increase recurrence also the distance between surface of the brain and the dura indicates severity of the brain atrophy. More the brain atrophy more are the chances of recurrence.

\section{CONCLUSIONS}

Chronic subdural Hematoma is essentially a benign condition that if treated properly can give very rewarding results.Antiplatelet and anticoagulant medications play a very important role in development of complications. Bilateral hematomas have more chances of development of acute deterioration in the form of Central herniation. Chronic subdural Hematoma with presence of risk factors should be followed closely for development of recurrence and complications. Chronic subdural Hematoma being essentially a disease of the elderly more care is required in view of disturb physiology in elderly.

\section{REFERENCES}

1. Abouzari M, Rashidi A, Rezaii J, Esfandiari K, Asadollahi M, Aleali $\mathrm{H}$, et al. The role of postoperative patient posture in the recurrence of traumatic chronic subdural hematoma after burr-hole surgery. Neurosurgery. 2007;61(1):794-797.

2. Asano Y, Hasuo M, Takahashi I, Shimosawa S. [Recurrent cases of chronic subdural hematoma--its clinical review and serial CT findings] No To Shinkei. 1992;44 (3):827-831.

3. Cenic A, Bhandari M, Reddy K. Management of chronic subdural hematoma: a national survey and literature review. Can J Neurol Sci. 2005;32 (5):501-506.

4. Chen JC, Levy ML. Causes, epidemiology, and risk factors of chronic subdural hematoma. Neurosurg Clin N Am. 2000;11 (2):399-406.

5. Erol FS, Topsakal C, Faik Ozveren M, Kaplan M, Tiftikci MT. Irrigation vs. closed drainage in the treatment of chronic subdural hematoma. J Clin Neurosci. 2005;12 (4):261-263.

6. Ishibashi A, Yokokura Y, Adachi H. A comparative study of treatments for chronic subdural hematoma: burr hole drainage versus burr hole drainage with irrigation. Kurume Med J. 2011;58 (6):35-39.

7. Jacobs B, Beems T, van der Vliet TM, Diaz-Arrastia RR, Borm GF, Vos PE. Computed tomography and outcome in moderate and severe traumatic brain injury: hematoma volume and midline shift revisited. J Neurotrauma. 2011;28 (1):203-215.

8. Jennett B, Bond M. Assessment of outcome after severe brain damage. Lancet. 1975;1 (5):480-484. 
9. Jennett B, Snoek J, Bond MR, Brooks N. Disability after severe head injury: observations on the use of the Glasgow Outcome Scale. J Neurol Neurosurg Psychiatry. 1981;44 (3):285-293.

10. Jeong SI, Kim SO, Won YS, Kwon YJ, Choi CS. Clinical Analysis of Risk Factors for Recurrence in Patients with Chronic Subdural Hematoma Undergoing Burr Hole Trephination. Korean J Neurotrauma. 2014;10 (6):1521.

11. Kang MS, Koh HS, Kwon HJ, Choi SW, Kim SH, Youm JY. Factors Influencing Recurrent Chronic Subdural Hematoma after Surgery. J Korean Neurosurg Soc. 2007;41 (1):11-15.

12. Kansal R, Nadkarni T, Goel A. Single versus double burr hole drainage of chronic subdural hematomas. A study of 267 cases. J Clin Neurosci. 2010;17 (4):428-429.

13. Krupp WF, Jans PJ. Treatment of chronic subdural haematoma with burr-hole craniostomy and closed drainage. Br J Neurosurg. 1995;9 (1):619-627.

14. Lee JY, Ebel H, Ernestus RI, Klug N. Various surgical treatments of chronic subdural hematoma and outcome in 172 patients: is membranectomy necessary? Surg Neurol. 2004;61 (3):523-527. discussion 527-528.

15. Lind CR, Lind CJ, Mee EW. Reduction in the number of repeated operations for the treatment of subacute and chronic subdural hematomas by placement of subdural drains. J Neurosurg. 2003;99 (4):44-46.

16. Mahapatra AK, Bansal S. Role of intracranial pressure monitoring in head injury: a prospective study. Neurol India. 1998;46 (6):109-114.

17. arkwalder TM, Seiler RW. Chronic subdural hematomas: to drain or not to drain? Neurosurgery. 1985;16 (1):185-188.

18. MRC CRASH Trial Collaborators. Perel P, Arango M, Clayton T, Edwards P, Komolafe E, et al. Predicting outcome after traumatic brain injury: practical prognostic models based on large cohort of international patients. BMJ. 2008;336 (6):425-429.

19. Nakaguchi H, Tanishima T, Yoshimasu N. Factors in the natural history of chronic subdural hematomas that influence their postoperative recurrence. J Neurosurg. 2001;95 (1):256-262.

Source of Support: Nil; Conflict of Interest: None

Submitted: 05-06-2019; Accepted: 18-07-2019; Published online: 25-07-2019 